\title{
Impact of obesity on outcomes in the management of localized adenocarcinoma of the esophagus and esophagogastric junction
}

Laura A. Healy, BSc, Aoife M. Ryan, BSc, Bussa Gopinath, FRCS, Suzanne Rowley, MSc, Patrick J. Byrne, PhD, and John V. Reynolds, MD

From the Departments of Clinical Surgery, St James's Hospital, and Trinity College Dublin, Dublin 8, Ireland.

Received for publication Dec 12, 2006; revisions received May 16, 2007; accepted for publication June 1, 2007.

Address for reprints: John V. Reynolds, MD, Department of Clinical Surgery and Dublin Molecular Medicine Center, Trinity Center for Health Sciences, St James's Hospital, Dublin 8, Ireland (E-mail: reynoljv@tcd.ie).

J Thorac Cardiovasc Surg 2007;134:1284-91 $0022-5223 / \$ 32.00$

Copyright () 2007 by The American Association for Thoracic Surgery

doi:10.1016/j.jtcvs.2007.06.037
Objective: Obesity trends in the Western world parallel the increased incidence of adenocarcinoma of the esophagus and esophagogastric junction. The implications of obesity on standard outcomes in the management of localized adenocarcinoma, particularly operative risks, have not been systematically addressed.

Methods: This retrospective analysis of prospectively collected data included 150 consecutive patients (36 [24\%] obese [body mass index $>30$ ] and 114 nonobese), of whom 43 were normal weight (body mass index 20-25) and 71 were overweight (body mass index 25-30). Eighty-one patients underwent multimodal therapy. The primary end points were in-hospital mortality and morbidity, and median and overall survivals.

Results: Thirty of 36 obese patients (84\%) had a body mass index from 30 to 35 . Compared with those of the nonobese cohort, obese patients had significantly increased respiratory complications $(P=.037)$, perioperative blood transfusions $(P=.021)$, anastomotic leaks $(P=.009)$, and length of stay $(P=.001)$, but no difference in mortality $(P=.582)$ or major respiratory complications $(P=.171)$. Median and overall survivals were equivalent $(P=.348)$ in both groups.

Conclusions: Obesity was associated with increased respiratory complications and anastomotic leak rates but not with major respiratory complications, mortality, or survival. These outcomes suggest that the added risks of obesity on standard outcomes in esophageal cancer surgery are modest and should not independently have a significant impact on risk assessment in esophageal cancer management.

$\mathrm{T}$ he pattern of esophageal cancer in Europe and North America has changed dramatically in recent decades, with a marked increase in the incidence of adenocarcinoma of the esophagus and esophagogastric junction. ${ }^{1}$ The explanation for this increase is unclear, but several risk factors, including chronic gastroesophageal reflux disease, obesity/diet, and Helicobacter pylori eradication, are plausibly linked with this emerging trend. ${ }^{1,2}$ Increasing epidemiologic evidence strongly links obesity and both the incidence of adenocarcinoma at these sites and death from this cancer. ${ }^{3-9}$

Consequently, the esophageal surgeon today is presented increasingly with the challenge of managing obese patients with adenocarcinoma of the esophagus or junction. The risk of operative mortality is up to $10 \%$, with an approximate $50 \%$ risk of morbidity. Some evidence suggests that these risks may be further increased by neoadjuvant therapy, particularly combination chemotherapy and radiation therapy. ${ }^{10-12}$ The management of localized disease has a major impact on quality of life over several months. ${ }^{13,14}$ Studies of the implications of obesity, defined by World Health Organization criteria ${ }^{15}$ as a body mass index (BMI) of greater than $30 \mathrm{~kg} / \mathrm{m}^{2}$, are therefore important, particularly with regard to risk assessment for esophageal 


\section{Abbreviations and Acronyms}

ARDS $=$ acute respiratory distress syndrome

BMI = body mass index

TRG = tumor regression grade

surgery. A combination of factors, including the association of obesity with existing comorbidities and medical complications, the complexity and duration of anesthesia and surgery, and insulin resistance, hormonal alterations, and chronic inflammation, ${ }^{16}$ permit the speculative thesis that obesity may increase the incidence of complications.

The principal risks after esophagectomy relate to respiratory complications. Intuitively, obese patients may be at higher risk, because pulmonary function in obese patients is characterized by reductions in functional residual capacity, expiratory reserve volume, and alveolar oxygen partial pressure, and an increase in the alveolar-arterial oxygen difference. ${ }^{17,18}$ The obese patient may consequently be more vulnerable to significant hypoxia from common postoperative problems, such as atelectasis. Abnormalities in control of breathing are also common, obstructive sleep apnea may occur in up to $40 \%$ of men with morbid obesity, and obstructive hypoventilation syndrome may also occur. ${ }^{19}$ Intraoperative or postoperative ventilation may be impaired by reduced compliance of the lung and chest wall and an increase in airway resistance. Moreover, when ventilator support is required postoperatively, weaning may be delayed because of this reduced chest wall compliance, and obese patients compared with nonobese patients have an up to a 5 -fold increase in oxygen uptake when changing from positive pressure ventilation to spontaneous breathing as a result of the increased work of breathing. ${ }^{16,17}$

Notwithstanding theoretic concerns, there is currently no reported systematic assessment of the relationship between obesity and standard outcomes in the management of localized cancer of the esophagus and esophagogastric junction. We report the experience of this unit and highlight the largely equivalent outcomes at this time between obese and nonobese cohorts.

\section{Materials and Methods}

We performed a retrospective analysis of a prospectively compiled database of patients with histologically proven adenocarcinoma of the esophagus or esophagogastric junction who underwent surgery in St James Hospital, Dublin, between January of 1998 and December of 2005. This study was approved by the hospital's ethics committee. Severely malnourished patients with a BMI less than $20 \mathrm{~kg} / \mathrm{m}^{2}(\mathrm{n}=5)$ and patients who underwent an emergency esophagectomy were excluded from the analysis. Preoperative weight and height were used to calculate BMI. The preoperative medical comorbidities and presenting symptoms were noted, as well as the reported and actual weight loss at time of diagnosis.
The patients' age, cigarette and alcohol consumption, performance status, initial routine blood results, and pulmonary function test scores were also noted. Obesity was defined as a BMI greater than $30 \mathrm{~kg} / \mathrm{m}^{2}$ per World Health Organization and National Institutes of Health Clinical Guidelines on the Identification, Evaluation, and Treatment of Overweight and Obesity in Adults. ${ }^{15,20}$

All patients had localized disease according to clinical, endoscopic, and computed tomography assessments. Endoscopic ultrasound was not routinely used. Fluorodeoxyglucose-positron emission tomography scanning has been routinely used since 2004. By using computed tomography criteria, the mediastinal, left gastric, and celiac lymph nodes were classified as N1 (invaded) if the maximal transverse diameter of these nodes was larger than $1 \mathrm{~cm}$. Localized disease was defined as $\mathrm{T}_{1-3}, \mathrm{~N}_{\mathrm{O}-1}$. All tumors of the esophagogastric junction were assigned as type I, II, or III, per Siewert and Stein. ${ }^{21}$ Type I is adenocarcinoma of the distal esophagus, usually arising in specialized intestinal metaplasia; type II is a true adenocarcinoma of the cardia arising immediately at the esophagogastric junction; and type III is a subcardial gastric carcinoma infiltrating the esophagogastric junction and distal esophagus from below.

Patients with type I and II tumors were considered for multimodal therapy involving a regimen of chemotherapy (cisplatin and fluorouracil) and radiation therapy (40-44 Gy in 15-20 fractions) as previously described. ${ }^{22}$ The majority (97\%) of patients undergoing an esophagectomy had a thoracotomy as a component of their surgical management, combined with the following: an abdominal and neck exploration (3-stage) for mid and upper-esophageal cancers or cancer arising in long-segment Barrett's esophagus, an abdominal exploration (2-stage) for most lower third and junctional tumors, or a total gastrectomy for junctional tumors with significant gastric extension (type III). All intrathoracic and cervical anastomoses were performed with interrupted single-layer 3-0 polydioxanone (Ethicon, Dublin, Ireland). A 2-field lymphadenectomy (abdominal and thoracic) was performed in all transthoracic cases. The length of the operation, intraoperative blood loss, and blood products given were all noted.

Unit protocol states that all patients receive epidural analgesia, be extubated immediately after surgery, and be managed in a high-dependency unit. All patients are fed enterally through a needle catheter jejunostomy from 12 hours postoperatively. A Gastrografin contrast study is performed routinely on day 8 postoperatively before initiating oral fluids. Throughout the hospitalization and at the 3-month follow-up, a dietitian monitored nutritional intake, complications, and body weight changes.

All complications from surgery to discharge from hospital were prospectively documented. Respiratory failure was defined as the requirement for mechanical ventilation more than 24 hours after surgery. Acute respiratory distress syndrome (ARDS) and multiple organ failure were defined per Bone and colleagues, ${ }^{23}$ sepsis required evidence of systemic inflammatory response syndrome with microbiological evidence of infection, and pneumonia required positive sputum cultures or clear clinical and radiographic evidence of consolidation.

Major respiratory complications for the purpose of this analysis were defined as pneumonia, empyema, respiratory failure, and 
ARDS. Any patient who experienced more than 1 major complication was only included in the analysis once.

The tumor stage was defined according to the TNM staging system and the American Joint Committee on Cancer classification. ${ }^{24}$ Fat-clearing methods were not used to increase lymph node yield. The definition of a curative resection was that all visible tumor was removed and that proximal, distal, and circumferential margins were free of tumor on histologic examination. In patients undergoing neoadjuvant therapy, the extent of residual carcinoma in the esophagectomy specimen was assigned to 1 of 5 tumor regression grade (TRG) categories per Mandard and colleagues: ${ }^{25}$ TRG1 represents fibrosis within the esophageal wall with no identifiable residual cancer cells, pathological complete response; TRG2 represents rare residual cancer cells scattered throughout the fibrosis; TRG3 represents an increase in the number of residual cancer cells, but fibrosis still predominant; TRG4 represents residual cancer cells outgrowing fibrosis; and TRG5 represents a complete absence of regression change. A TRG of 1 or 2 is deemed a good response, and a TRG of 3 to 5 is deemed a poor response.

\section{Statistical Methods}

Statistical analysis was performed using the Statistical Package for the Social Sciences Version 11.0 for Windows (SPSS Inc, Chicago, Ill). Analysis of variance was used to identify significant differences between BMI categories. Postoperative complications were compared using univariate chi-square tests. The primary comparison was between obese and nonobese cohorts, but some comparisons were also made between 3 cohorts: obese, overweight, and normal weight. Multinominal logistic regression models were used to account for potential confounding factors associated with postoperative complications. The models included age, sex, heavy alcohol intake, and current smokers. We obtained hazard ratios and $95 \%$ confidence interval levels from the models for the obese and nonobese groups. Actuarial survival was calculated from the date of first treatment by the Kaplan-Meier method, and comparisons between the groups were made by the log-rank test.

\section{Results}

\section{Patient Demographics}

During this period, resection for localized disease with curative intent (anticipated clear margins, R0) was undertaken in 150 patients, 81 of whom $(54 \%)$ had neoadjuvant chemoradiation therapy before surgery according to the unit protocol. Forty-three patients $(29 \%)$ were of normal weight (BMI $20-25 \mathrm{~kg} / \mathrm{m}^{2}$ ), with a weight range between 50 and 85 $\mathrm{kg} ; 70$ patients $(47 \%)$ were overweight (BMI $25-30 \mathrm{~kg} / \mathrm{m}^{2}$ ), with a weight range of 80 and $130 \mathrm{~kg}$; and 36 patients $(24 \%)$ were obese $\left(\mathrm{BMI}>30 \mathrm{~kg} / \mathrm{m}^{2}\right)$, with a weight range between 80 and $130 \mathrm{~kg}$. The median BMI was $27 \mathrm{~kg} / \mathrm{m}^{2}$. In the obese group, 30 patients $(83 \%)$ had a BMI between 30 and 35 $\mathrm{kg} / \mathrm{m}^{2}(80-115 \mathrm{~kg}), 4$ patients $(11 \%)$ had a BMI between 35 and $40 \mathrm{~kg} / \mathrm{m}^{2}(101-125 \mathrm{~kg})$, and 2 patients $(5 \%)$ had a BMI greater than $40 \mathrm{~kg} / \mathrm{m}^{2}$ (131 kg) (Table 1).

The clinical pattern of presentation was similar in both groups. There was no significant difference between obese
TABLE 1. Demographics of obese and nonobese groups

\begin{tabular}{|c|c|c|c|}
\hline Demographic details & $\begin{array}{l}\text { Nonobese } \\
(\mathrm{n}=114)\end{array}$ & $\begin{array}{l}\text { Obese } \\
(n=36)\end{array}$ & $P$ value \\
\hline Sex: male/female & $98 / 16$ & $31 / 5$ & .216 \\
\hline Age: median (range), y & $62(37-79)$ & $62(29-79)$ & .521 \\
\hline \multicolumn{4}{|l|}{ Symptoms } \\
\hline \multicolumn{4}{|l|}{ Dysphagia } \\
\hline Heartburn & $81(71)$ & $29(81)$ & .183 \\
\hline Regurgitation & $36(32)$ & $11(31)$ & .541 \\
\hline Weight loss $>10 \%$ & $39(34)$ & $12(33)$ & .546 \\
\hline \multirow[t]{2}{*}{ History of GERD $>1 \mathrm{y}$} & $34(33)$ & $4(13)$ & .059 \\
\hline & $31(27)$ & $10(28)$ & .562 \\
\hline \multicolumn{4}{|l|}{ Smoking and alcohol } \\
\hline Never smoked & $41(36)$ & $7(20)$ & \\
\hline Ex-smoker (>1 y) & $46(40)$ & $22(61)$ & \\
\hline Current smoker & $27(24)$ & $7(19)$ & .076 \\
\hline Heavy alcohol & $20(18)$ & $9(25)$ & .352 \\
\hline \multicolumn{4}{|l|}{$\begin{array}{l}\text { Comorbid disease and } \\
\text { performance status }\end{array}$} \\
\hline Cardiovascular & $35(31)$ & $17(47)$ & .033 \\
\hline Respiratory disease & $19(17)$ & $8(22)$ & .299 \\
\hline Type II diabetes & $9(8)$ & $2(6)$ & .258 \\
\hline Karnovsky > 90\% & $108(96)$ & 34 (95) & .367 \\
\hline ECOG: fully active & $79(70)$ & $26(73)$ & .345 \\
\hline ASA grade I or 2 & $95(87)$ & $34(94)$ & .322 \\
\hline \multicolumn{4}{|l|}{ Pulmonary function tests } \\
\hline $\mathrm{FEV}_{1}$ & $3.1(1-5.5)$ & $2.7(1.1-4.1)$ & .046 \\
\hline FVC & $4.0(2.0-6.4)$ & $3.8(1.7-5.9)$ & .297 \\
\hline $\mathrm{FEV}_{1} / \mathrm{FVC}$ ratio & $79(42-94)$ & $74(53-89)$ & .014 \\
\hline
\end{tabular}

GERD, Gastroesophageal reflux disease; ECOG, Eastern Cooperative Oncology Group; ASA, American Surgical Association; $F E V_{1}$, forced expiratory volume in 1 second; $F V C$, forced vital capacity.

and nonobese patients in known type 2 diabetes, respiratory disease, or performance status. The incidence of cardiovascular disease was influenced by BMI; 7 of 43 patients $(16 \%)$ with a BMI between 20 and $25 \mathrm{~kg} / \mathrm{m}^{2}$ had a history of cardiovascular disease, compared with 28 of 70 patients (40\%) with a BMI between 25 and $30 \mathrm{~kg} / \mathrm{m}^{2}$ and 17 of 36 patients $(47 \%)$ with a BMI more than $30 \mathrm{~kg} / \mathrm{m}^{2}(P=.003)$.

In obese patients, preoperative forced expiratory volume in 1 second $(P=.046)$ and the forced expiratory volume in 1 second/forced vital capacity ratio $(P=.014)$ were significantly inferior compared with those of the nonobese group. This did not relate to tobacco consumption; the highest percentage of current smokers $(40 \%)$ was in the normal weight groups compared with the overweight (14\%) and obese $(19 \%)$ groups $(P=.042)$.

\section{Treatment Characteristics}

There was no significant difference in esophagogastric junction classification among the BMI categories. Some $67 \%$ of obese patients received multimodal therapy compared with $50 \%$ of nonobese patients $(P=.018)$. The majority of 
TABLE 2. Tumor type, treatment details, and pathology

\begin{tabular}{lccc}
\hline & $\begin{array}{c}\text { Nonobese } \\
\text { (n = 114) }\end{array}$ & $\begin{array}{c}\text { Obese } \\
(\mathbf{n}=\mathbf{3 6})\end{array}$ & P value \\
\hline Tumor location & & & \\
Lower: & & & \\
Type 1 & $53(47)$ & $11(31)$ & .290 \\
$\quad$ Type 2 & $42(38)$ & $21(60)$ & \\
$\quad$ Type 3 & $17(15)$ & $3(9)$ & \\
Mid & $2(2)$ & 0 & \\
Associated Barrett's & $50(44)$ & $20(56)$ & .180 \\
Type of surgery & & & \\
2-stage esophagectomy & $96(84)$ & $33(92)$ & .486 \\
3-stage esophagectomy & $14(12)$ & $1(3)$ & \\
Transhiatal & $3(3)$ & $1(3)$ & \\
Thoracoabdominal & $2(2)$ & $1(3)$ & \\
Multimodal therapy & $57(50)$ & $24(67)$ & .018 \\
Pathology & & & \\
Stage 0/1 & $22(19)$ & $11(31)$ & \\
Stage 2 & $39(34)$ & $16(44)$ & \\
Stage 3 & $52(46)$ & $9(25)$ & .013 \\
Node positive & $70(61)$ & $20(53)$ & .082 \\
R0 & $93(84)$ & $29(83)$ & .257 \\
No. of nodes analyzed & $15(5-46)$ & $10(4-28)$ & .008 \\
Response to neoadjuvant & & & \\
$\quad$ therapy (n = 81) & & & \\
TRG 1 and 2 & $26(45)$ & $10(42)$ & .495 \\
TRG 3, 4, and 5 & $31(55)$ & $14(58)$ & \\
Pathologic complete & $12(21)$ & $3(12)$ & \\
$\quad$ response & & \\
\hline
\end{tabular}

TRG, Tumor regression grade.

patients in both groups underwent a 2-stage esophagectomy (Table 2).

\section{Pathologic Analysis}

The R0 resection rate was $83 \%$ and $84 \%$ in the obese and nonobese groups, respectively $(P=.198)$. In patients undergoing multimodal therapy, the complete pathologic response rate was $12 \%$ in the obese group compared with $21 \%$ in the nonobese group $(P=.425)$, and there were no differences between groups in terms of achieving a major histomorphologic response (TRG1 or 2) at the primary site, observed in $42 \%$ and $45 \%$ in the obese and nonobese groups, respectively $(P=.495)$. In this cohort, nonobese patients had more advanced cancer according to pathologic stage, with $46 \%$ of patients presenting with stage 3 disease versus $25 \%$ of obese patients $(P=.013)$. There was no significant difference in nodal status; the majority of patients were node-positive: $53 \%$ in the obese group versus $61 \%$ in the nonobese group $(P=.082)$. The median nodal yield was significantly $(P=.008)$ greater in the nonobese group at 15 (5-46), compared with 10 (4-28) in the obese patient. Nonobese patients had a significantly greater number of positive nodes than obese patients: $3(0-25)$ versus 1
TABLE 3. In-hospital postoperative morbidity and mortality

\begin{tabular}{lccc}
\hline & $\begin{array}{c}\text { Nonobese } \\
(\mathbf{n}=\mathbf{1 1 4})\end{array}$ & $\begin{array}{c}\text { Obese } \\
(\mathbf{n}=\mathbf{3 6})\end{array}$ & $\boldsymbol{P}$ value \\
\hline Mortality & $7(6)$ & $2(6)$ & .582 \\
Sepsis & $12(11)$ & $5(14)$ & .386 \\
All respiratory complications & $43(38)$ & $21(58)$ & .037 \\
Major respiratory complication* & $21(19)$ & $10(28)$ & .171 \\
Respiratory failure & $12(11)$ & $2(6)$ & .299 \\
ARDS & $7(6)$ & $2(6)$ & .630 \\
Pneumonia & $15(13)$ & $4(11)$ & .502 \\
Empyema & 0 & $2(6)$ & .057 \\
Pleural effusion & $27(24)$ & $15(42)$ & .032 \\
Atelectasis & $9(8)$ & $5(14)$ & .121 \\
Thromboembolism & $3(3)$ & $1(3)$ & .436 \\
Major wound complications & $3(2)$ & 0 & .760 \\
Arrhythmia & $13(11)$ & $7(19)$ & .168 \\
Anastomotic leak & $2(2)$ & $5(14)$ & .009 \\
Renal dysfunction & $9(8)$ & $2(6)$ & .482 \\
Blood productst & & & \\
$\quad 0$ & $64(58)$ & $13(39)$ & .021 \\
1-2 units & $38(34)$ & $12(36)$ & \\
$>2$ units & $8(7)$ & $8(24)$ & \\
\hline ARDS Acute & &
\end{tabular}

ARDS, Acute respiratory distress syndrome. ${ }^{*}$ Number of patients with a major respiratory complication (ie, pneumonia, respiratory failure, ARDS, or empyema). †Blood products given intraoperatively or within 48 hours postoperatively.

$(0-8)(P=.037)$. Barrett's epithelium was present in $56 \%$ of resected specimens in the obese group and $44 \%$ in the nonobese group $(P=.180)$.

\section{Surgery and In-hospital Complications}

There was no significant difference $(P=.150)$ between the mean duration of surgery in the obese group (350 minutes) and nonobese group (320 minutes). The use of blood products intraoperatively and in the first 48 hours after surgery in the obese group $(P=.021)$ was increased, with $24 \%$ of patients requiring over 2 units of blood compared with $7 \%$ in the nonobese group (Table 3).

In-hospital mortality was $6 \%$ in both groups. Twenty-one of 36 obese patients $(58 \%)$ had a respiratory complication, compared with 43 of 114 nonobese patients $(38 \%)(P=$ .037); however, there was no significant difference between obese and nonobese groups in major respiratory complications, including pneumonia $(P=.502)$, ARDS $(P=.630)$, and respiratory failure $(P=.299)$. There were 2 cases of empyema, both in the obese group $(P=.057)$. An anastomotic leak (3 radiologic and 2 clinical) developed in 5 patients in the obese group, compared with 1 clinical and 1 radiologic leak in the nonobese group $(P=.009)$. All were managed nonoperatively, and 1 clinical leak in both groups was managed with endoprosthesis. There were no significant differences between groups with respect to venous thromboembolism $(P=.436)$, major wound problems $(P=$ 
TABLE 4. Relative hazard ratios for obesity and postoperative complication

\begin{tabular}{lccc}
\hline & P value & OR & 95\% CI \\
\hline All respiratory complications & .014 & 2.6 & $1.2-5.9$ \\
Major respiratory & .283 & 2.7 & $1.1-6.4$ \\
complications & & & \\
Pleural effusion & .019 & 2.7 & $1.1-6.4$ \\
Anastomotic leak & .006 & 11 & $2.0-61.7$ \\
\hline
\end{tabular}

$O R$, Odds ratio; $\mathrm{Cl}$, confidence interval. Adjusted for age, sex, heavy alcohol intake, and current smokers.

$.760)$, arrhythmias $(P=.168)$, and renal dysfunction $(P=$ .482 ). The median stay in the high-dependency unit postoperatively was 4 days $(0-14$ days) in the obese group compared with 4 days ( $0-32$ days) in the nonobese group $(P=.937)$. The median hospital stay was significantly $(P=$ $.001)$ greater at 23 days (13-94 days) in the obese group compared with 18 days (1-61 days) in the nonobese group.

On multivariate analysis (Table 4), obese patients were 2.6 times more likely to have any respiratory complication $(P=.014), 2.7$ times more likely to have a pleural effusion $(P=.019)$, and 11 times more likely to have an anastomotic leak $(P=.006)$ than nonobese patients.

\section{Postoperative Nutrition}

All patients were nutritionally supported via a feeding jejunostomy in the postoperative period. The median duration of postoperative nutrition support (full feeding or overnight feeding) was 16 days (10-80 days) in the obese group and 15 days (2-53 days) in the nonobese group $(P=.128)$. Obese patients lost more weight postoperatively as inpatients compared with nonobese patients $(4.7[0-26] \mathrm{kg}$ vs $2.8[0-14] \mathrm{kg} ; P=.048)$.

\section{Survival}

At a median follow-up of 39 months, the median survival (Figure 1) in the obese group was 27 months, compared with 25 months in the nonobese group $(P=.348)$. The 1,3 , and 5 -year survivals were $75 \%, 46 \%$, and $46 \%$, respectively, in the obese group, and $75 \%, 34 \%$, and $22 \%$, respectively, in the nonobese group.

\section{Discussion}

Obesity, defined as a BMI greater than $30 \mathrm{~kg} / \mathrm{m}^{2}$, has increased in incidence in the developed world in the last decade. Approximately $30 \%$ of the population are obese in the United States, and more than 100,000 operations were performed for morbid obesity in 2004. ${ }^{26,27}$ The increased incidence of adenocarcinoma of the esophagus and esophagogastric junction in recent decades parallels the increasing prevalence of obesity. In an Irish cohort we recently reported that $82 \%$ of patients with adenocarcinoma of the esophagus or esophagogastric junction were overweight or obese, and that obesity in males was associated with a 4-fold increase risk of adenocarcinoma. ${ }^{8}$ The explanation for this association is unclear. One possible mechanism links the typical male central adiposity with chronic gastroesophageal reflux disease, both of which are independently associated with adenocarcinoma of the esophagus and junction. ${ }^{28}$ In addition to a mechanical link, the pleiotropic properties of the adipocyte have come under scrutiny, because adipocytes from central fat may have endocrine, paracrine, and immunologic properties. ${ }^{29}$ This may be manifested in the metabolic syndrome, which is a constellation of atherogenic dyslipidemia, elevated blood pressure, and elevated blood glucose associated with insulin resistance. The proinflammatory response associated with central adiposity and the metabolic syndrome may, at least theoretically, promote inflammation and tumorigenic pathways that are relevant to esophageal adenocarcinoma and other tumor types. $^{16}$

Surgery for esophageal cancer is associated with a significant risk of morbidity and mortality, and has a major impact on quality of life. ${ }^{1}$ A recent review of 70,000 patients reported a mortality of $6.7 \%$ between 1990 and $2000 .^{30}$ The combined Veterans Administration experience for the same period reported a major morbidity rate of approximately $50 \%$ and a mortality rate of $10 \% .{ }^{10}$ In the United Kingdom, McCulloch and colleagues ${ }^{31}$ reported a $12 \%$ in-hospital mortality rate from a multicenter series. The recent advent of multimodality regimens, particularly neoadjuvant combination chemotherapy and radiation therapy, may further increase operative risks. ${ }^{11,12}$ It is unassailable that there is no common elective cancer surgery that carries the same risks. In an era of risk stratification and informed consent, data on the impact of obesity on outcomes after esophagectomy are increasingly important, and to our knowledge this is the first report specifically addressing the relationship of obesity to the standard outcome indicators of an esophageal unit.

In this study, no increase in in-hospital mortality was observed in the obese cohort. Respiratory complications were rigorously recorded, and an increased incidence of complications was observed in the obese cohort. There was, however, no increase in the more major complications of postoperative pneumonia, respiratory failure, or ARDS in the obese group. The incidence of anastomotic leaks was increased in the obese group; however, the incidence of clinically evident leaks was not significantly different. The incidence of anastomotic leak was low (3\%), compared with the reported incidence of up to $10 \%$ post-esophagectomy. ${ }^{32,33}$ On univariate analysis, obesity was the only factor associated with anastomotic leak, and there was no relationship to incidence and age, sex, American Surgical Association grade, smoking, or alcohol use. Obesity was associated with the risk of anasto- 


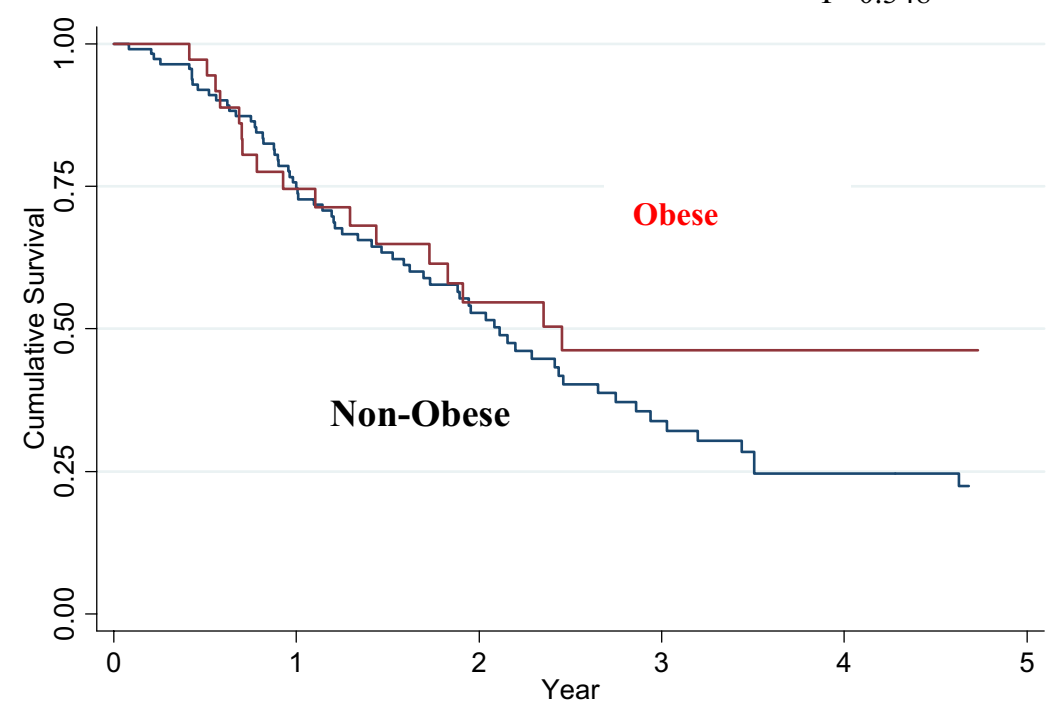

Obese median survival $=29$ months

Non obese median survival $=25$ months

Non-Obese

\begin{tabular}{|l|c|c|c|}
\hline Survival time & No at Risk & Deaths & \% Survival \\
\hline 0 year & 114 & 0 & $100 \%$ \\
\hline 1 year & 81 & 23 & $75 \%$ \\
\hline y years & 21 & 36 & $34 \%$ \\
\hline 5 years & 10 & 7 & $22 \%$ \\
\hline
\end{tabular}

Obese

\begin{tabular}{|l|c|c|c|}
\hline Survival time & No at Risk & Deaths & \% Survival \\
\hline 0 year & 36 & 0 & $100 \%$ \\
\hline 1 year & 26 & 8 & $75 \%$ \\
\hline 3 years & 11 & 9 & $46 \%$ \\
\hline 5 years & 6 & 0 & $46 \%$ \\
\hline
\end{tabular}

Figure 1. Survival.

motic leak after resection and primary anastomosis for left-sided colonic emergencies. ${ }^{34}$ The factors involved in the increased leaks observed in the obese group in this study are unclear, but we speculate that the dependence of touch and judgment rather than clear visibility of the right gastroepiploic vessels, as well as increased tension of the conduit in the high thorax or the cervical site, may compromise the vascularity of the gastric anastomotic site. Other factors, such as diabetes and cardiovascular disease, may also be contributory, but this was not evident in this analysis.

The concern that obese patients would have a higher incidence of wound infections and dehiscence could not be verified, and the incidence of clinical venous thromboembolism was low in this study in which all patients received prophylactic low molecular weight heparin. Blood transfu- sion requirements were significantly increased in the obese group, and obesity was associated with a significantly longer duration of postoperative hospital stay.

Esophagectomy is associated with significant metabolic, endocrine, and immunoinflammatory changes. A similar spectrum of response is seen after major blunt trauma. In studies of patients with blunt trauma, however, and in contrast with this study, Smith-Choban and colleagues ${ }^{35}$ reported a $42 \%$ mortality in obese patients versus $7 \%$ for nonobese patients, and respiratory failure as the result of ARDS was the primary cause. In a study by Neville and colleagues $^{36}$ on 242 patients admitted to the intensive care unit after blunt trauma, 62 were obese and the odds ratio of mortality was 5.7 compared with the nonobese cohort. In a study of patients undergoing liver transplantation, obesity 
was associated with an increased incidence of multiple organ failure. ${ }^{37}$ The lack of major added risks associated with obesity in this study is consistent with reports of equivalent complication rates in obese and nonobese patients undergoing cardiac surgery, in which the increased risk of complications seems to be evident only in patients with extreme obesity (BMI $\left.>40 \mathrm{~kg} / \mathrm{m}^{2}\right){ }^{38}$ Only 2 patients in this study had a BMI greater than $40 \mathrm{~kg} / \mathrm{m}^{2}$; both patients had sleep apnea and 1 patient had obesity hypoventilation syndrome, but both survived without major complications. It is clear that risk assessment in the morbidly obese patient cannot be inferred from this study of predominantly patients with a BMI from 30 to $35 \mathrm{~kg} / \mathrm{m}^{2}$.

Frequent symptoms of reflux are associated with increased risks of Barrett's esophagus, and these risks are substantially elevated by obesity and smoking. ${ }^{39}$ In a population-based study $^{39}$ in obese patients (BMI > 30), the risk of Barrett's esophagus was minimal with no reflux symptoms (odds ratio: $0.795 \%$ confidence interval $0.2-2.4$ ) and increased dramatically with weekly reflux symptoms (odds ratio: 34.4 95\% confidence interval 6.3-188). There was no difference in the reported incidence of gastroesophageal reflux disease in this population, which may explain the lack of association between obesity and Barrett's esophagus. This study also addressed the standard oncologic indicators, and there was no differences in RO resection rate, tumor response rate, and survival. Nodal yield was less in the obese cohort, perhaps reflecting the lack of routine fat-clearing mechanisms by pathologists.

\section{Limitations}

The limitations of the study are acknowledged, particularly the retrospective nature of the analysis. Prospective study in this unit now encompasses assessment of the metabolic syndrome, comprehensive respiratory physiology analysis pretreatment, documentation on intraoperative and early postoperative dynamics in respiratory physiology, and studies of immune function and metabolism in the perioperative period. Underweight patients (BMI $<20 \mathrm{~kg} / \mathrm{m}^{2}$ ) were also excluded because of the small number $(\mathrm{n}=5)$ of the cohort and the fact that they represent a high-risk group. When all patients were included and the population was divided into quintiles or tertiles, a significant association of the highest quintile or tertile with anastomotic leaks and respiratory complications remained evident (data not shown).

\section{Conclusions}

This study shows that obese patients undergoing surgical or multimodality management of localized adenocarcinoma of the esophagus or esophagogastric junction have a longer hospital stay, an increased incidence of respiratory complications and radiologic anastomotic leaks, and greater requirements for blood products compared with nonobese patients. There was no difference in mortality or major complications, and the cancer survival outcomes are equivalent. Risk stratification is the ultimate motivation for establishing complication rates in obese patients undergoing esophageal surgery, and this study shows that surgery was undertaken in an obese population, predominantly patients with a BMI between 30 and $35 \mathrm{~kg} / \mathrm{m}^{2}$, with no major increased risk of serious morbidity or mortality.

\section{References}

1. Enzinger PC, Mayer RJ. Esophageal cancer. N Engl J Med. 2003;349: 2241-52.

2. Devesa SS, Blot WJ, Fraumeni JF. Changing patterns in the incidence of esophageal and gastric carcinoma in the United States. Cancer. 1998;83:2049-53.

3. Engel LS, Chow WH, Vaughan TL, Gammon MD, Risch HA, Stanford $\mathrm{JL}$, et al. Population attributable risks of esophageal and gastric cancers. J Natl Cancer Inst. 2003;95:1404-13.

4. Brown LM, Swanson CA, Gridley G, Swanson GM, Schoenberg JB, Greenberg RS, et al. Adenocarcinoma of the esophagus: role of obesity and diet. J Natl Cancer Inst. 1995;87:104-9.

5. Vaughan TL, Davis S, Kristal A, Thomas DB. Obesity, alcohol, and tobacco as risk factors for cancers of the esophagus and gastric cardia: adenocarcinoma versus squamous cell carcinoma. Cancer Epid Biomark Prev. 1995;4:85-92.

6. Chow WH, Blot WJ, Vaughan TL, Risch HA, Gammon MD, Stanford $\mathrm{JL}$, et al. Body mass index and risk of adenocarcinoma of the esophagus and gastric cardia. J Natl Cancer Inst. 1998;90:150-5.

7. Lagergren J, Bergström R, Nyrén O. Association between body mass index and adenocarcinoma of the esophagus and gastric cardia. Ann Intern Med. 1999;130:883-90.

8. Ryan AM, Rowley SP, Fitzgerald AP, Ravi N, Reynolds JV. Adenocarcinoma of the esophagus and gastric cardia: male preponderance in association with obesity. Eur J Cancer. 2006;42:1151-8.

9. Calle EE, Rodriguez C, Walker-Thurmund K, Thun MJ. Overweight, obesity and mortality from cancer in a prospectively studied cohort of U.S. adults. $N$ Engl J Med. 2003;348:1625-38.

10. Bailey SH, Bull DA, Harpole DH, Rentz JJ, Neumayer LA, Pappas $\mathrm{TN}$, et al. Outcomes after esophagectomy: a ten-year prospective cohort. Ann Thorac Surg. 2003;75:217-22.

11. Fiorica F, DiBona D, Schepis F, Licata A, Shahied L, Venturi A, et al. Preoperative chemoradiotherapy for esophageal cancer: a systematic review and meta-analysis. Gut. 2004;53:925-30.

12. Reynolds JV, Ravi N, Hollywood D, Kennedy MJ, Rowley S, Ryan A, et al. Neoadjuvant chemoradiation may increase the risk of respiratory complications and sepsis after transthoracic esophagectomy $J$ Thorac Cardiovasc Surg. 2006;132:549-55.

13. Blazeby JM, Sandford E, Falk SJ, Alderson D, Donovan JL. Health related quality of life during neoadjuvant therapy and surgery for localised esophageal cancer. Cancer. 2005;103:1791-9.

14. Reynolds JV, Mc Laughlin R, Moore J, Rowley S, Ravi N, Byrne PJ. Prospective evaluation of quality of life in patients with localised esophageal cancer treated by multimodality therapy or surgery alone. Br J Surg. 2006;93:1084-90.

15. World Health Organisation Consultation on Obesity. Preventing and managing the global epidemic: report of a WHO consultation on Obesity, Geneva, 3-5 June 1997, 1-276. Geneva, Switzerland: World Health Organization; 1998.

16. Balkwill F, Mantovani A. Inflammation and cancer: back to Virchow? Lancet. 2001;357:539-45.

17. Adams JP, Murphy PG. Obesity in anaesthesia and intensive care. $\mathrm{Br} \mathrm{J}$ Anaesth. 2000;85:91-108.

18. Flanchbaum L, Choban PS. Surgical implications of obesity. Ann Rev Med. 1998;49:215-34.

19. Brooks-Brumm JA. Predictors of postoperative pulmonary complications following abdominal surgery. Chest. 1997;111:564-71.

20. National Institutes of Health. Clinical Guidelines on the Identification, Evaluation and Treatment of Overweight and Obesity in Adults: The Evidence Report. Obes Res. 1998;6(suppl 2):51S-209S. 
21. Siewert JR, Stein HJ. Classification of adenocarcinoma of the esophagogastric junction. Br J Surg. 1998;85:1457-9.

22. Walsh T, Noonan N, Hollywood D, Kelly A, Keeling N, Hennessy TPJ. A comparison of multimodal therapy and surgery for esophageal adenocarcinoma. $N$ Engl J Med. 1996;335:462-7.

23. Bone RC, Sibbald WJ, Spring CL. The ACCP-SCCM consensus conference on sepsis and organ failure. Chest. 1992;101:1481-3.

24. Greene FL, Page DL, Fleming ID, Fritz A, Balch CM, Haller DG, et al., editors. American Joint Committee on Cancer. AJCC Cancer Staging Manual, 6th ed. New York: Springer-Verlag; 2002.

25. Mandard AM, Dalibard F, Mandard JC, Marnay J, Henry Amar M, Petiot JF, et al. Pathologic assessment of tumor regression after preoperative chemoradiotherapy of esophageal carcinoma. Cancer. 1994; 73:2680-6.

26. Overweight, obesity, and health risk. National Task Force on the Prevention and Treatment of Obesity. Arch Intern Med. 2000;160:898-94.

27. Steinbrook R. Surgery for severe obesity. N Engl J Med. 2004;350: 1075-9.

28. Lagergren J. Controversies surrounding body mass, reflux, and risk of esophageal adenocarcinoma. Lancet Oncol. 2006;7:347-9.

29. Kershaw EE, Flier JS. Adipose tissue as an endocrine organ. J Clin Endocrinol Metab. 2004;89:2548-56.

30. Jamieson GG, Mathew G, Ludeman R, Wayman J, Myers JC, Devitt PG. Postoperative mortality after esophagectomy and problems in reporting its rate. Br J Surg. 2004;91:943-7.

31. McCulloch P, Ward J, Tekkis P. Mortality and morbidity in gastroesophageal cancer surgery: initial results of ASCOT multicenter prospective study. BMJ. 2003;327:1192-7.
32. Junemann-Ramirez M, Awan MY, Khan ZM, Rahmamim JS. Anastomotic leakage post esophagectomy for esophageal carcinoma: retrospective analysis of predictive factors, management and influence on longterm survival in a high volume centre. Eur J Cardiothorac Surg. 2005;27:3-7.

33. Briel JW, Tamhanker AP, Hagen JA, DeMeester SR, Johansson J, Choustoulakis E, et al. Prevalence and risk factors for ischaemia, leak, and stricture of esophageal anastomosis: gastric pull up versus colonic interposition. J Am Coll Surg. 2004;198:536-41.

34. Bionda S, Pares D, Kreisler E, Marti Rague J, Fraccalvieri D, Garcia Ruiz A, et al. anastomotic dehiscence after resection and primary anastomosis in left sided colonic emergencies. Dis Colon Rectum. 2005;48:2272-80.

35. Smith-Choban P, Weireter LJ, Maynes C. Obesity and increased mortality in blunt trauma. J Trauma. 1991;31:1253-7.

36. Neville AL, Brown CVR, Weng J, Demetriades D, Velmahos GC. Obesity is an independent risk factor of mortality in severely injured blunt trauma patients. Arch Surg. 2004;139:983-7.

37. Sawyer RG, Pelletier SJ, Pruett TL. Increased early morbidity and mortality with acceptable long-term function in severely obese patients undergoing liver transplantation. Clin Transplant. 1999; 13:126-30

38. Wigfiled CH, Lindsey JD, Munoz A, Chopra PS, Edwards NM, Love RB. Is extreme obesity a risk factor for cardiac surgery? An analysis of patients with a BMI $>40$. Eur J Cadiothorac Surg. 2006;29:434-40.

39. Smith KJ, O'Brien SM, Smithers BM, Gotley DC, Webb PM, Green $\mathrm{AC}$, et al. Interactions among smoking, obesity, and symptoms of acid reflux in Barrett's esophagus. Cancer Epidemiol Biomarkers Prev. 2005;14:2481-6. 